Easterlin-types and Frustrated Achievers:

The Heterogeneous Effects of Income Changes on Life Satisfaction

Leonardo Becchetti, Luisa Corrado and Fiammetta Rossetti

April 2008

CWPE 0816 


\title{
Easterlin-types and Frustrated Achievers: the Heterogeneous Effects of Income Changes on Happiness*
}

\author{
Leonardo Becchetti \\ University of Rome Tor Vergata \\ Luisa Corrado ${ }^{\dagger}$ \\ University of Rome Tor Vergata and University of Cambridge \\ Fiammetta Rossetti \\ University of Rome Tor Vergata
}

May 11, 2009

\begin{abstract}
Keywords: income-happiness relationship, frustrated achievement, mixture models. JEL: C14, C23, I30.
\end{abstract}

${ }^{*}$ We thank Luigino Bruni, Rafael Di Tella, Lisa Ferrer-i-Carbonell, Alessandra Pelloni and Giovanni Trovato for their comments and suggestions. The usual disclaimer applies.

${ }^{\dagger}$ Marie Curie Fellow, Faculty of Economics, University of Cambridge and Associate |Professor at the University of Rome Tor Vergata. e-mail: lc242@econ.cam.ac.uk. Luisa Corrado acknowledges the support of the Marie-Curie IEF Fellowship EUMICRO 039326. 


\section{Abstract}

We investigate the relationship between money and happiness across the waves of the British Household Panel Study by using a latent class approach which accounts for slope heterogeneity, omitted variable bias and departures from normality assumptions. Our findings reveal the presence of a vast majority of "Easterlin-type" individuals with positive but very weak relationship between changes in income and changes in happiness and a small minority (2 percent) of "frustrated achievers" with negative relationship. Such share is much below descriptive evidence on frustrated achievement (17.5 percent). The probability of belonging to such group is shown to be positively related with divorced status and negatively related to education and relative (personal to reference group) income. Our interpretation of these results is that the standard concave money-happiness relationship provides a partial and incomplete picture of the complex nexus between happiness and income as it does not take into account two important phenomena: the role of peers and of reference group income and that of the dynamics between realisations and expectations.

\section{Introduction}

The literature on the determinants of life satisfaction has incredibly boomed in the last few years both in terms of richness of contributions and published papers in leading economic journals. Its success among economists is probably due to the opportunity of testing empirically standard a priori assumptions on the relationship between the utility function ${ }^{1}$ and its arguments - one of the basic tenets of economic theory. More specifically, with regard to the issue at stake in this paper, theoretical models and risk measures ${ }^{2}$ postulate nonsatiation concerning the effects of income on utility. The obvious rationale is that money is a means of exchange which can be used to purchase an ample variety of market goods. Hence, its marginal utility should not stop from being positive, even when individuals possess large amounts of it.

Empirical studies on the determinants of happiness generally find support for this hypothesis with some qualifications. On the one side, it is argued that "money buys happiness" since almost all contributions find a positive, even though often nonlinear, relationship between life satisfaction and personal income (see, among others, Easterlin, 1995; Frey and Stutzer, 2000; Di Tella et al. 2005). Evidence on this stance is reinforced i) by empirical results on panel data which control for fixed effects (usually interpreted as time invariant inherited individual traits) and analyse the relationship between changes in income and changes in happiness (Winkelmann and Winkelmann, 1998; Ravallion and Lokshin, 2001; Ferrer-i-Carbonell and Frijters, 2004; Ferrer-i-Carbonell, 2005 and Clark et al., 2005) and ii) by those papers which try to solve the causality problem identifying exogenous changes in income (such as tsunami related effects on income, lottery wins or changes in real income in Russia and East Germany after transition and reunification) and find a significant effect of them on life satisfaction (Gardner and Oswald, 2006b; Frijters et al., 2004a, 2004b and 2006).

On the other side, some authors have a different way of looking at the issue and emphasize that money "does not buy", or has very weak effects on happiness. Their arguments are based on panel data evidence showing that the dynamic relationship between the two variables is much weaker than the cross-sectional one and the gap in per capita income between rich and poor countries does not find correspondence into an equal gap in terms of life satisfaction (Diener et al., 1999; Nettle, 2005 and Layard, 2005). In a study on the impact of economic growth in China Kahneman and Krueger (2007) show no increase in

\footnotetext{
${ }^{1}$ Utility and happiness are not exactly the same concept. But, by definition, something is useful if it enhances our wellbeing and life satisfaction. Therefore, a straightforward link between utility and happiness may be easily established and such link is conventionally assumed in most of the happiness literature.

${ }^{2}$ This is the case for instance of first order stochastic dominance.
} 
reported life satisfaction from 1994 to 2005; in fact, the percentage of people who say they are dissatisfied has increased, and the percentage who say they are satisfied has decreased. Finally, the existence of "frustrated achievers" - individuals who associate positive changes in income with negative changes in happiness - has widely been documented from a descriptive point of view (Becchetti et al., 2007; Graham and Pettinato, 2002).

Based on this descriptive evidence we aim to extend the literature by testing slope homogeneity in the relationship between the two variables. The underlying intuition is that money does not cause the same change in life satisfaction for all individuals and heterogeneous reactions are due to the intermediation of different factors (education, gender, religion, age and relational status) which crucially determine our attitude toward money and our reaction to income changes. If this were true, the aggregate effects of money on happiness should depend not only on factors affecting all individuals in the same way, but also by changes in the composition of the different "clusters" which have heterogeneous attitudes and beliefs toward the role of money on human happiness.

\section{Our methodological approach}

By using a latent class approach in panel data in which individual declarations on life satisfaction are repeated over time, it is possible to account for slope heterogeneity and classify individuals into different groups according to their specific life satisfaction response to changes in real per capita income. In this way we can identify the exact proportion of those for whom "income buys happiness" (or positive changes in per capita income are accompanied by positive changes in self declared life satisfaction) and, at the opposite, in case of a negative coefficient, the so called group of "frustrated achievers" for whom income does not buy happiness. ${ }^{3}$

An interpretation for adopting a latent approach is that there is a group of people for whom unobserved negative life outcomes are systematically correlated with rises in income. For example, life cycle patterns in income are likely similar. More generally, the relationship between income and happiness is clearly not causal and it seems quite plausible that it is not the income changes that are causing the decline in happiness among people for whom a negative relationship is identified. It may be a third factor, as already mentioned, or it may be reverse causation - some people throw themselves into their work when they are unhappy.

Slope heterogeneity is not the only reason for choosing the latent class technique (a linear specification with interaction terms would be sufficient if this were the only problem). The mixture approach has a more general important advantage over other specifications. A correct epistemological approach tells us that all models are probably imperfect synthetic views of the reality and are falsifiable by later and more updated versions. This is also true in our case. More complex nonlinear functional forms can capture some nonlinearities in the money-income relationship better than the standard linear approach but are also rigid and may hide some misspecification. The latent class approach is, on our opinion, an "epistemologically correct" solution to the problem of model inadequacy since it allows to handle properly the misspecification of the link function and of the response distribution through the mixture components (MacLachlan and Peel, 2000, Aitkin et al., 2003, Alfó and Trovato, 2004).

\footnotetext{
${ }^{3}$ By focusing on this last group of people and analyzing the determinants of frustrated achievement we may provide evidence which sheds light on the problematic side of the income-happiness relationship.

More specifically, with the latent class approach, we may discover that the aggregate weak impact of income on happiness (obtained under the assumption of slope homogeneity) found in many papers may depend not only on the above mentioned dampening effects and concurring factors, but also on the existence and growth of a group of "frustrated achievers". The identification of such group and the analysis of the factors affecting their attitude as well as that of the alternative group of "satisfied achievers" may provide useful policy advices to policymakers which are sometime surprised by the lack of positive reaction in terms of electoral consensus of good economic performances.
} 
More specifically, model misspecification, omitted variable bias and departures from normality are three typical problems which are hardly escapable in econometric estimates. They all generate biases which affect the random component by altering its distribution. Standard approaches assume that the problem does not exist, while the latent class approach tries to handle the issue by working on the error term and isolating a systematic component which can be related to different latent factors (not all of them identifiable with available controls).

To sum up, the mixture approach may provide fundamental advances in empirical happiness studies since it is the only way to: i) correct in a proper way the misspecification in the functional link between income and life satisfaction and take into account problems of omitted variable bias and departures from normality assumption; ii) identify properly the drivers of the money-life satisfaction relationship; ii) test for the existence of frustrated achievers beyond descriptive correlations (given that it is reasonable to think that an eventual negative econometric link between changes in income and changes in happiness may exist only for a minority of individuals and cannot therefore be detected when we assume slope homogeneity in our sample). The only paper which is close to our approach in the literature is that of Clark et al. (2005) who examine with a mixture model the relationship between levels of income and life satisfaction on the European Household Survey Panel. Our paper has four main differences with respect to the above mentioned contribution. First, we look at first differences and not at levels in the money-happiness relationship, consistently with our focus on frustrated achievement. Second, we consider as dependent variable life and not income satisfaction. This choice is more consistent with our goal of testing for the existence of frustrated achievement (frustrated achievement has to do with overall life and not just income satisfaction). Third, individuals interviewed in our sample come from one country only, therefore solving potential cultural biases in reported life satisfaction generated by intercountry analysis. ${ }^{4}$ Last but not least, differently from Clark et al. (2005) we employ a two stage procedure. In the first stage the mixture model selects the clusters with homogeneous latent structures. In the second stage we investigate the nature of these latent factors in order to better understand what is beyond the moneyhappiness relationship. To this purpose we correlate some sociological and economic variables with cluster membership by using a multinomial conditional logit model. In this second stage we consider as potential regressors some socio-demographic traits (regional location, education, gender, age, type of work, etc.). Since we want to capture social as well as inter-personal comparison, we also introduce relative income measures with respect to reference groups.

The paper is divided into four sections including introduction and conclusions. In the second section we present descriptive evidence on episodes of frustrated achievement, while in the third section we discuss our econometric findings. The fourth section concludes.

\subsection{Data source and descriptive findings}

We investigate the dynamics of the relationship between income and life satisfaction on data from the British Household Panel Survey (May 2007) ${ }^{5}$, covering the years 1991-2005. ${ }^{6}$ Table 1 describes the

\footnotetext{
${ }^{4}$ Consider however that racial differences within the UK may be a factor of heterogeneity as serious as that existing in intercountry comparisons. This does not allow us to overcome completely the problem.

${ }^{5}$ The BHPS is an annual survey consisting of a nationally representative sample of about 5,500 households recruited in 1991, containing a total of approximately 10,000 interviewed individuals. The sample is a stratified clustered design drawn from the Postcode Address File and all residents present at those addresses at the first wave of the survey were designated as panel members. These same individuals are re-interviewed each successive year and, if they split-off from original households to form new households, they are followed and all adult members of these households are also interviewed.

${ }^{6}$ The survey covers both individual and households in the UK. The main topics covered are: i) Individual details core subjects include neighborhood and individual demographics, current employment, labor and non-labour income, health and caring, employment history, values and opinions. Continuous measures of income and employment histories over the life of the survey; ii) Household details - core subjects include size and condition of dwelling, ownership, housing costs,
} 
variables and Table 2 provides a summary statistics. All the variables relate to answers in the BHPS to questions on life-satisfaction, income and socio-demographic characteristics as reported in the Table at the time of the interview.

In databases containing both cross-sectional and time series informations it is possible to single out idiosyncratic time invariant characteristics of the observed individuals (interpreted in this literature as inherited personality traits) and concentrate on the "within dimension" which is more reliable than the "between" one. ${ }^{7}$ This is a fundamental advantage in presence of a ordinal indicator based on a subjective valuation such as self declared life satisfaction. It is easy to figure out that it is more problematic to assess whether a "quite satisfied" declaration of one individual corresponds to a "quite satisfied" declaration of another, than relying on the fact that the same individual has increased his life satisfaction if he declares himself "quite satisfied" one year and "very satisfied" the following one. ${ }^{8}$

The life satisfaction question in the BHPS is a standard question in which individuals are asked to evaluate their overall level of life satisfaction on a 1-7 scale.

By inspecting properties of this variable in levels we find that its average is 5.23 and its standard deviation 1.30 (Table 3). ${ }^{9}$ The transition matrix (Table 3) shows that persistence is high for those at the lowest (1) or high levels of life satisfaction (from 5 to 7 ). On the contrary, when individuals declare levels of life satsifaction from 2 to 4 there is a higher probability of moving one step ahead than remaining in the same condition in the following year. This indicates that respondents seem either entrenched in the lowest life satisfaction level or, if starting from slightly higher values, they tend to move upwards toward the 5-7 levels. This dynamics seems confirmed by the fact that values below the diagonal are much smaller than those above it, indicating that a move from lowest to highest life satisfaction levels is more likely to occur than viceversa.

To introduce the issue of the heterogeneity in the relationship between changes in life satisfaction and changes in income consider that, while for many individuals an increase in real per capita income is associated with substantially positive variations in life satisfaction, the alternative (association with negative changes) is generally defined as "frustrated achievement" (Graham and Pettinato, 2002).

A starting point in our empirical analysis is therefore the detection of the presence of frustrated achievement in descriptive statistics. According to the standard definition, a "frustrated achiever" is an individual who reports at the same time a positive variation in personal income and a negative variation in self declared life satisfaction from one year to another. Three alternative conditions are those of "satisfied achievers" (a positive change in income accompanied by a positive change in life satisfaction), "frustrated losers" (a negative change in income accompanied by a negative change in life satisfaction) and "satisfied losers" (a negative change in income accompanied by a positive change in life satisfaction). The four above mentioned types do not cover all the possibilities since we did not consider in the above taxonomy all those situations in which life satisfaction (as it is often the case) or personal income remain the same in a one year change. Table 4 shows that episodes of frustrated achievement account for 17.5 percent of all individual-year changes in our sample. The share is slightly higher with respect to what found in the same analysis on the German Socioeconomic Panel in the period going from 1984 to 2004 where,

consumer durable. Rotating core (cyclical every two waves - individual questionnaire.iii) Health and caring - attitude towards cost/payments for health care. Distribution of wealth - social justice, government's roles and responsibilities, environment, management of household expenditures.

${ }^{7}$ Summary statistics of database variables used in our empirical analysis are presented in Table 1.

${ }^{8}$ However, several authors come in support of the plausibility of interpersonal cardinal comparability by arguing that individuals are able to recognize or predict self declared happiness of others (Ferrer-i-Carbonell, 2005; Frijters 2004; Diener and Lucas 1999) and translate verbal labels moreless into the same numerical values.

${ }^{9}$ The number of observations in this Table coincides with the number of one-year sequences available for the life satisfaction variable. It must necessarily be lower than the total number of life satisfaction observations in Table 2 given that, in the first year of the sample period we cannot measure transition from the previous year 
on a total of 168,626 observations, episodes of frustrated achievement accounted for 16 percent of total individual-year observations (Becchetti et al., 2007). Surprisingly, episodes of frustrated achievement are slightly higher than those of satisfied achievement (16 percent). The reader can easily verify that the sum of the four above mentioned states (combining frustrated and satisfied achievers and losers) is far from covering all individual-year observations, consistently with our transition matrix in Table 3 showing that, in a large number of cases, life satisfaction does not change from one year to another (indifferent achievers and indifferent losers account respectively for 29.76 and 16 percent observations). This finding reflects a typical characteristic of this variable which is varying slowly across time. By adding to frustrated achievers all those whose level of life satisfaction does not change after an increase in real personal income, we reach half of the sample.

Clearly, descriptive evidence on frustrated achievement may produce spurious results since we cannot control for factors different from income changes in explaining life satisfaction changes. Standard econometric analysis is however not exhaustive. If we really want to identify subgroups of individuals with heterogeneous life satisfaction reactions to per capita income changes, we need to remove the homogeneity assumption in the relationship between the two variables. Given that episodes of frustrated achievement presumably account only for a minority of cases, standard methods based on the assumption of slope homogeneity across individuals will be hiding heterogeneity (and frustrated achievement) behind a mildly positive average coefficient. Hence, under such assumption it is not possible to test whether there is a subgroup of individuals for which the relationship is indeed negative.

This is why we decide to use latent class techniques to model slope heterogeneity in this relationship between changes in income and reported life satisfaction.

\section{The Econometric Model}

To model the correlation between time variations in income and in life satisfaction status, we perform a latent class analysis. The finite mixture approach allows us to consider properly the correlations among outcomes and latent factors (Alfó and Trovato, 2004). The model assigns observations to different groups with homogenous latent structures captured by the random terms in the slope. More formally, while the outcome variable is ordinal in levels, it is not ordinal in first-differences and we assume that the change in individual life satisfaction status is given by:

$$
h_{i}=x_{i}^{\mathrm{T}} \beta_{i}+\varepsilon_{i}
$$

where $x_{i}^{\mathrm{T}}$ is the matrix of covariates. In the formulation above we have generalized the simple random intercept model to the "random coefficients" model. In particular, as stressed by Alfó and Trovato (2004), the coefficients $\beta_{i}$ can be expressed as $\hat{\beta}+u_{i}$, where $\hat{\beta}$ is the fixed part of coefficient and $u_{i}$ are the latent factors. Hence, the slopes are specific to each individual and have to be estimated together with the other model parameters. If this is true Clark et al. (2005) emphasize that this is an additive source of unobserved heterogeneity and that heterogeneity has to be modeled by the random terms. We use a finite mixture approach in which we assume that the parameter vector $\delta=\left(\hat{\beta}, u_{1}, \ldots u_{C}\right)$ is distributed over a finite number of points $c=1, \ldots, C$.

As it is well known (Laird, 1978), the estimate of a mixing distribution is a discrete distribution on a finite number of locations, say $C$, whose likelihood function can be expressed as:

$$
L(\cdot)=\prod_{i=1}^{n}\left\{\sum_{c=1}^{C} f\left(h_{i}, x_{i}, u_{c}\right) \pi_{c}\right\}=\prod_{i=1}^{n}\left\{\sum_{c=1}^{C}\left[f_{i c} \pi_{c}\right]\right\}
$$


Locations, $u_{c}$, and corresponding masses, $\pi_{c}$, represent unknown parameters, as well as $C$, which is treated as fixed and estimated via formal model selection techniques. Following Aitkin (1999), the estimation of the complete parameter vector, $\delta$, can be derived as follows

$$
\frac{\partial \log [L(\delta)]}{\partial \delta}=\frac{\partial \ell(\delta)}{\partial \delta}=\sum_{i=1}^{n} \sum_{c=1}^{C}\left(\frac{\pi_{c} f_{i c}}{\sum_{c=1}^{C} \pi_{c} f_{i c}}\right) \frac{\partial \log f_{i c}}{\partial \delta}=\sum_{i=1}^{n} \sum_{c=1}^{C} w_{i c} \frac{\partial \log f_{i c}}{\partial \delta}
$$

where $w_{i c}$ represents the posterior probability that the $i-t h$ unit comes from the $c-t h$ component of the mixture. Equating the derivatives to zero gives corresponding likelihood equations which are weighted sums of those from an ordinary GLM with weights $w_{i c}$. Solving these equations for a given set of weights, and updating the weights from the current parameter estimates defines an EM algorithm.

From a computational perspective, the EM algorithm is quite simple to implement (see Clark et al. (2005) and Alfo' and Trovato (2004)). The optimum number of mass points is chosen by Penalized Bayesian Criteria such as Bayesian Information Criteria, Aitkin Information Criteria and Constrained Aitkin Information Criteria. Locations and posterior probabilities are used to classify individuals across groups on the basis of the posterior probabilities $\widehat{\omega}_{i c}$ individual can be classified in the $l-t h$ group if $\widehat{\omega}_{i l}=\max \left(\widehat{\omega}_{i 1}, \ldots, \widehat{\omega}_{i c}\right)$.

\section{Results}

The endogenous groups are identified by mixture models ${ }^{10}$. In the base model the dependent variable (the first difference of the 1-7 life satisfaction indicator) is regressed on an intercept and on the log difference of the real household income ${ }^{11}$. At the basis of the mixture approach is the assumption that our global relationship between changes in life satisfaction and changes in income is obtained by weighting the $C$ different functions corresponding to the different groups (see equations 2 and 3 ). As Table 5 shows the optimal number of components of the unknown mixture has been chosen by looking at the probability of inclusion in the various groups, finding that two mass points best represent the local areas of support of the true distribution (for a discussion on the optimal number of components see McLachlan and Peel, 2000). ${ }^{12}$ These locations are used to classify individuals across groups on the basis of the posterior probabilities $\widehat{\omega}_{i c}$. The peculiarity of our semi-parametric approach is that, within each group, there are homogenous values for the random effects, conditional on the covariates chosen in the estimation. This implies that individuals with the same unobservable attitude towards changes in income, as represented by the random component of the coefficient, will be classified in the same group if they have the same maximized posterior probability of belonging to that group. Hence, in each group, individuals are characterised by the same latent factors capturing the effects of different attitudes (from cultural background, unobservable family traits, etc.) towards changes in income.

Table 6 reports the finite mixture estimates against the benchmark of a fixed effects homogenous parameter estimation ${ }^{13}$. Prior probabilities of belonging to each of the two groups are reported at the

\footnotetext{
${ }^{10}$ For the estimation we use the package Generalised Linear and Latent Mixed Models (GLLAMM), see www.gllamm.org.

${ }^{11}$ We control for household member effects by introducing the number of children and family status among regressors in the group membership equation. We prefer this approach to the use of a household equivalised income since it is more flexible and does not impose arbitrary structure to our variables. A robustness check using real personal income is also performed with results which are not substantially different from those shown here.

12 The table shows that, when the number of groups is above two, the probability of inclusion in some of the groups is almost nil.

${ }^{13} \mathrm{As}$ it is common in this literature, we assume that our dependent variable has enough variation to be approximated by a continuous one and therefore we estimate a model in which the link is gaussian..
} 
bottom of the Table. In addition we also have the location for each individual, that is, the sensitivity of changes in life satisfaction to changes in income. Reported findings confirm that it is not possible to detect frustrated achievers if we assume slope homogeneity. The average coefficient is .0033, positive as expected, but very weak and not significant. It shows that, on average, an increase in real personal income has very poor effects on life satisfaction.

Going beyond sample average results and considering the sign of the location parameters for the two endogenous clusters, we can identify two types of individuals: i) the Easterlin types with total coefficient (average plus random component) of around 0.06. ${ }^{14}$ By approximating the first differenced life satisfaction variable with a normal distribution and computing elasticities we find that the above mentioned coefficient implies that, doubling the average sample log real personal yearly income (approximately at 10,800 pounds), raises by only 0.5 percent the level of life satisfaction ${ }^{15}$; ii) "frustrated achievers" (with negative total coefficient) for which income does not buy life satisfaction (or an improvement in monetary well being is indeed accompanied by a higher probability of suffering a reduction in life satisfaction $)^{16}$. The Easterlin type individuals constitute the large majority (98 percent) of the sample, while frustrated achievers are only small part of it (around 2 percent). These few numbers identify, to our opinion, two very important facts: i) for the large majority of the population of richer economies, such as the UK, changes in income do produce positive (but weak) effects on life satisfaction. This result is also consistent with cross-sectional evidence on the concavity of the relationship between domestic per capita GDP and life satisfaction at the country level showing that, beyond a level of income corresponding roughly to the average EU level, further increases in income have almost negligible effects on life satisfaction (Frey and Stutzer, 2005); ii) the share of frustrated achievers exists but is marginal and much below the descriptive finding of frustrated achievement (which accounts for 17.5 percent of the individual-year observations). Such sharp drop is justified by the difference between the two measures. Descriptive evidence just looks at association between the two phenomena of changes in income and life satisfaction in the opposite direction, while econometric analysis identifies a subset of individuals with a significant econometric effect in the same direction. ${ }^{17}$ Descriptive evidence provided in Table 7 gives some preliminary hints on variables which may affect participation to the two groups. Considered regressors are standard demographic factors (age, gender, race, geographical location, family status, professional status and education) as well as the level of personal income and a measure of relative income. All the variables relate to the status at the time of the interview.

To understand the importance of this latter set of variables we consider, as many other recent works in the area (Easterlin, 1995; Blanchflower and Oswald, 2004), the effect of the reference group status on consumption and wellbeing is strong in our societies. Individuals tend to "keep-up-with-the-Joneses" but there are different ways of defining reference groups.

\footnotetext{
${ }^{14}$ We use the them "Easterlin types" because our estimate provides indirect evidence that the impact of income change on happiness is relatively small, consistently with the well known empirical evidence of the "Easterlin paradox" showing that the share of very happy US citizens has remained constant and slightly declined in the postwar period, notwithstanding the sustained increase in per capita income

${ }^{15}$ Such elasticity is different from the total coefficient of the estimate presented in Table 3 since the latter is drawn from a linear-logarithmic estimate.

${ }^{16}$ Actually the sign of the relationship also implies cases in which reductions of income reduce the probability of a negative change in happiness and therefore individuals of this group are both "frustrated achievers" and "satisfied losers". We keep on defining them as frustrated achievers for simplicity.

${ }^{17}$ Consider that it is much easier to find many individual-year cases in which we observe both positive changes in happiness and negative changes in income than situations in which, for a given individual, a regression of changes in income on changes in happiness across the overall sample period exhibits a significant and negative coefficient. In the first case we may have a spurious temporary negative association between the two variables, in the second case we have a non spurious relationship (random components in the mixture approach capture effects of omitted variables) which is calculated over a long time period.
} 
Clark et al. (2006) adopt a "people-like-me" approach ${ }^{18}$ when they evaluate how relative income (based on gender, education and average wage by region) is affecting individual life satisfaction alongside individual income. ${ }^{19}$ Other potential peer groups are those with whom the individual comes into close daily contact: her family, friends and work colleagues. With respect to this aspect very few papers, to our knowledge, have considered this alternative set of reference-groups. ${ }^{20}$ Galizzi and Lang (1998) show that observable behaviour (quits) depends on own wage relative to colleagues' wages. Brown et al. (2006), using employer-employee data from the British Workplace Employee Relations Survey show that the position (rank) of the individual in the firm wage distribution is positively correlated with their pay, their achievement, the satisfaction with the amount of influence they have, and the respect they receive. Finally Clark (1996) using BHPS data shows that individuals report lower job satisfaction scores the higher are the wages of other workers in the household.

Using information on socio-economic class from BHPS we have defined a set of reference groups of the "people-like-me" type (based on gender, education, location and age) which is analogous to that used by Ferrer-i-Carbonell (2005) and of the peer-effect type (based on gender, age and working environment). After defining the potential determinants of group affiliation, we look at characteristics of the two clusters from a descriptive point of view. We find that the share of males (around 46 percent in the group of non frustrated achievers) drops considerably to 30 percent in the Frustrated Achiever group (Table 7). FAs also have significantly higher shares of divorced individuals (17.7 against 8.4 percent). Only 20 percent of FAs have high school degree against against 37 percent of non FAs. Relative income of FAs appears significantly lower. All the above mentioned differences in mean values among FAs and non FAs are significant at 5 percent level.

The next step of our analysis is to verify whether descriptive evidence is confirmed by econometric estimates.

The dependent variable in the logit estimate takes the value of one if the individual belongs to the cluster of frustrated achievers and zero otherwise.

Results from the pooled and random effect logit estimates are presented in Tables 8 and 9, respectively. It is much easier to find many individual-year cases in which we have both positive change in life satisfaction and negative change in income than situations in which, for a given individual a regression of changes in income on changes in life satisfaction across the overall sample period exhibit a significant and negative coefficient. In the first case we may have a spurious temporary negative association between the two variables, in the second case we have a non spurious relationship (random components in the mixture approach capture effects of omitted variable) which is calculated over a long time period. In both cases we consider three different specifications. In the first we add the level of personal income to

\footnotetext{
${ }^{18}$ Another criteria uses location to identify reference-groups. Aslam and Corrado (2006) assess the determinants of wellbeing using a multilevel modeling approach based on data at the national, regional and individual levels. Empirical findings support the idea that well-being is strongly dependent upon group effects at the regional level, alongside more specific individual characteristics. Blanchflower and Oswald (2004) use GSS data over the 1972-1998 period, and use average income by US State as reference group income. Luttmer (2005) follows a geographic approach as well, and calculates average income by local area identified in several waves of the US National Survey of Families and Households. The author finds a negative slope with life satisfaction, conditional on the respondent individual income.

${ }^{19}$ The regression approach of calculating the income of "people like me" is also used by Clark and Oswald (1996) on the first wave of the British Household Panel Survey (BHPS) data. The estimated coefficients on household and reference group income in a job satisfaction equation are statistically equal and opposite, which is consistent with a "fully relative" utility function. To paraphrase Easterlin (1995), these results document that "increasing the income of all increases the happiness of no-one".

${ }^{20}$ Wave 3 (2006) of the European Social Survey has introduced a survey question where individuals are first asked "How important is it to you to compare your income with other people's incomes?" They are then asked "Whose income would you be most likely to compare your own with?", with responses on a showcard of Work colleagues, Family members, Friends, and Others.
} 
a set of common regressors, in the second we add also the "people-like-me" relative income variable (in levels and first differences), while in the third the "peer effect" relative income variable (in levels and first differences).

Our findings reveal four main results which are significant and robust across different specifications and estimation methods. First, we find a positive (and significant) effect of the divorced status on the probability of being a FA. Two interpretations here are equally plausible. The first is that having partners with whom you can share bigger cakes gives more enjoyment than just getting a bigger cake on your own. The second is that marriage has also risk sharing effects and therefore reduces the likelihood that those with positive income changes may suffer from a reduction in life satisfaction due to the higher risk they run by depending on only one source of income. This second interpretation is not fully convincing in a first difference estimate since the positive change of income per se remains good news also for separated and divorced individuals. The reasoning may be valid only if we believe that the higher risk of depending on a single source of income may have persistent negative effects on life satisfaction, or if separated and divorced individuals have higher probabilities of associated changes in income requirements which are higher than the observed change in the income earned (i.e. higher alimonies to be paid, etc.). In a similar way, the hidden variable we do not measure here is changes in expectations: it may happen that for divorced individuals changes in expectations are systematically higher than changes in income, thereby determining the negative effect on life satisfaction.

The second relevant result, the negative sign of the higher education dummy, seems to suggest that education has a "Maslow" effect on individuals increasing their immaterial needs and moderating income expectations.

Two final nice findings in our estimate are related to the role of personal and relative income. When we introduce personal income alone we find that it is negatively correlated with the probability of being a frustrated achiever. When we look at relative income (under both the peer and people-like-me measures) we find as expected a negative sign of the first difference of the relative income variable. This finding is consistent with the positive impact of relative income on life satisfaction. In short, the increase of personal income with respect to that of the peers has a significant and independent positive impact on life satisfaction. Finally, geographical location also seems to matter since location in Scotland and Wales significantly increase the probability of falling in the group of frustrated achievers.

Other results seem weaker as they are confirmed in only one of the two types of estimates. This is the case of the gender effect in pooled estimates and of the number of children effect in the random effect estimates.

\section{Conclusions}

The aim of this paper is to show how, in the analysis of the relationship between money and life satisfaction, a latent class estimation approach adds new fundamental insights that the average coefficients produced under the standard slope homogeneity assumptions are unable to reveal.

Our findings using BHPS data reveal the presence of a large group of "Easterlin-type" individuals with positive but weak relationship between changes in income and changes in life satisfaction, and a small minority (2 percent) of frustrated achievers with a weak but negatively significant relationship between changes in income and changes in self declared life satisfaction. The probability of belonging to such group is shown to be positively correlated with divorced status and negatively related to education, personal and relative income. Geographical location seems also to matter.

An overall interpretation of our findings is that, due to the relatively high level of per capita income, almost all individuals in the UK are weakly sensitive to income changes per se, and therefore may be conceived as lying on the flat part of the concave life satisfaction-income relationship. Furthermore, the 
estimation of the mixture model suggests that the traditional assumption of nonsatiation in the concave money-utility function may be rejected in very few special cases in which we have the combination of several factors. This implies that, for frustrated achievers, the curve is not just flat, but it may even become negatively inclined in presence of given conditions related to relative income, marital status, geographical location and education. Increasing gaps between expectations and realizations (e.g. in terms of family expenditure requirements), more positive income changes of one's own peers, and lack of close mates with which to share an increased prosperity, may turn the income-life satisfaction relationship from a positive into a negative one.

\section{References}

[1] Aitkin, M.A., Francis, B. and Hinde, J. (2003). Statistical Modelling in GLIM. Oxford University Press, Oxford, 2nd edition.

[2] Alfò M. and Trovato G., (2004). Semiparametric mixture models for multivariate count data, with application. Econometrics Journal, Royal Economic Society, vol. 7, pp. 426-454.

[3] Aslam, A. and Corrado L (2007). No Man is an Island, the Inter-personal Determinants of Regional Well-Being in Europe. Cambridge Working Paper in Economics 0717.

[4] Becchetti L., Castriota S. and Rossetti F. (2007). The social consequences of economic growth: The relationship between real household income and self-declared tolerance. Working Paper CEIS.

[5] Becchetti L. Rossetti F., 2007, When money does not buy happiness: the case of "frustrated achievers" CEIS working paper.

[6] Blanchflower, D.G. and Oswald, A.J. (2004). Well-being over time in Britain and the USA. Journal of Public Economics, vol. 88, pp. 1359-1386.

[7] Bloom, E.D., D. Canning and J. Sevilla (2003). Geography and poverty traps, Journal of Economic Growth, 8, 355-378.

[8] Brown, G., Gardner, J., Oswald, A.J. and Qian, J. (2006). Does Wage Rank Affect Employees' Wellbeing? University of Warwick, mimeo.

[9] Clark, A.E. (1996). L'utilité est-elle relative? Analyse à l'aide de données sur les ménages. Economie et Prévision, vol.121, pp. 151-164.

[10] Clark, A.E. (1999). Are Wages Habit-Forming? Evidence from Micro Data. Journal of Economic Behavior and Organization, vol. 39, pp. 179-200.

[11] Clark, A.E., Etilé, F., Postel-Vinay, F., Senik, C., and Van der Straeten, K. (2005). Heterogeneity in reported well-being: Evidence from twelve European countries. Economic Journal, vol. 115, pp.C118C132.

[12] Diener, E. Lucas, R.E. (1999 ). Well-being: The foundations of Hedonic Psychology. Russell Sage Foundation.

[13] Diener, E., Suh, E., Lucas, R., and Smith, H. (1999). Subjective well-being: Three decades of progress. Psychological Bulletin, vol. 125, pp. 276-302. 
[14] Easterlin, R.A. (1995). Will raising the incomes of all increase the happiness of all? Journal of Economic Behavior $\&$ Organization, vol. 27, pp. 35-47

[15] Easterlin, R.A. (2000). The Worldwide Standard of Living since 1800. The Journal of Economic Perspectives, vol. 14, pp. 7-26

[16] Frey, B.S. and Stutzer A. (2000). Maximising Happiness? German Economic Review, vol. 1, pp. $145-167$.

[17] Ferrer-i-Carbonell, A. (2005). Income and well-being: An empirical analysis of the comparison income effect. Journal of Public Economics, vol. 89, pp. 997-1019.

[18] Ferrer-i-Carbonell, A. and Frijters, P. (2004). How important is methodology for the estimates of the determinants of happiness? The Economic Journal, vol. 114, pp. 641-659.

[19] Frijters, P., Shields, M.A., and Haisken-DeNew, J.P. (2004a). Money does matter! Evidence from increasing real incomes in East Germany following reunification. American Economic Review, vol. 94, pp. $730-741$.

[20] Frijters, P., Shields, M.A., and Haisken-DeNew, J.P. (2004b). Changes in the pattern and determinants of life satisfaction in Germany following reunification. Journal of Human Resources, vol. 39, pp. 649-674.

[21] Frijters, P., Geishecker, I., Shields, M.A. and Haisken-DeNew, J.P. (2006). Can the large swings in Russian life satisfaction be explained by ups and downs in real incomes? Scandinavian Journal of Economics, forthcoming.

[22] Galizzi, M. and Lang, K. (1998). Relative wages, wage growth and quit behavior. Journal of Labor Economics, vol. 16, pp. 367-391.

[23] Gardner J. and Oswald A. J. (2006). Do divorcing couples become happier by breaking up? Journal of the Royal Statistical Society, vol. 169, pp. 319-336.

[24] Graham, C. and Pettinato, S. (2002). Happiness and Hardship: Opportunity and Insecurity in New Market Economies. Washington, D.C.: The Brookings Institution Press.

[25] Kahneman, D. and Krueger, A. (2006). Developments in the Measurement of Subjective Well-Being. Journal of Economic Perspectives, 20 (1), pp. 3-24.

[26] Laird, N.M. (1978), Nonparametric Maximum Likelihood Estimation of a Mixing Distribution." Journal of American Statistical Association, 73, 805-811.

[27] Layard, R. (2005). Happiness. Lessons from a New Science, London: Allen Lane.

[28] Luttmer, E. (2005). Neighbors as negatives: Relative earnings and well-being. Quarterly Journal of Economics, vol. 120, pp. 963-1002.

[29] MacLachlan, G. and Peel, D. (2000), Finite Mixture Models, John Wiley \& Sons Inc.

[30] Nettle, D. (2005). Happiness: The Science Behind Your Smile. Oxford: Oxford University Press.

[31] Paap, R., H.K. van Dijk (1998). Distribution and mobility of wealth of nations. European Economic Review, 42. 
[32] Paap, R., P.H. Franses and Dick van Dijk (2005). Does Africa grow slower than Asia,Latin America and the Middle East? Evidence from a new data-based classification method, Journal of Development Economics, 77, 553-570.

[33] Ravallion M. and Lokshin M. (2001). Identifying Welfare Effects from Subjective Questions. Economica, vol. 68, pp. 335-357.

[34] Ravallion, M. and Lokshin, M., (2002). Self-rated economic welfare in Russia. European Economic Review, vol. 46, pp. 1453-1473.

[35] Winkelmann L. and Winkelmann R. (1998).Why Are the Unemployed So Unhappy? Evidence from Panel Data. Economica, vol. 65, pp. 1-15. 
Table 1. List of Variables

\begin{tabular}{|c|c|c|}
\hline Variable & Response & Description \\
\hline Satisfaction & Ordered 1-7 & "How dissatisfied or satisfied are you with your life overall?" \\
\hline Age & Binary & $\begin{array}{l}\text { Dummy variables for Aged less than } 25 \text { years; Aged between } 25 \text {-34 years; } \\
\text { Aged between } 35-44 \text { years; Aged between } 45-54 \text { years; } \\
\text { Aged between } 55-64 \text { years. }\end{array}$ \\
\hline Male & Binary & Sex of Individual: Male, Female. \\
\hline White & Binary & $\begin{array}{l}\text { Which of these ethnic groups is appropriate to indicate your cultural } \\
\text { background: a. White; b. Mixed; c. Asian or Asian British; } \\
\text { d. Black or Black British; e. Chinese or other ethnic group. }\end{array}$ \\
\hline Area & Binary & $\begin{array}{l}\text { Dummy variables for Area of residence: a. England; b. Wales; } \\
\text { c. Scotland; d. Northern Ireland. }\end{array}$ \\
\hline Religious & Binary & $\begin{array}{l}\text { Dummy variable if belonging to any of these religious denominations: } \\
\text { Catholic; Presbyterian; Church of Ireland; Methodist; Baptist; } \\
\text { Free Presbyterian; Brethren; Protestant; Other Christian; Jewish; } \\
\text { Other non-Christian. }\end{array}$ \\
\hline Children & Cardinal & Number of own children in household \\
\hline Marital Status & Binary & $\begin{array}{l}\text { Dummy variables for present legal marital status: a. Married, } \\
\text { b. Separated; c. Divorced; d. Widowed } 6 \text {. Never married. }\end{array}$ \\
\hline Higher Education & $\begin{array}{l}\text { Binary } \\
\text { Binary }\end{array}$ & $\begin{array}{l}\text { Dummy if the individual went through further education } \\
\text { Dummy variables derived from the question } \\
\text { "Socio economic group: most recent job": } \\
\text { a. Employers; b. Managers; c. Professional; d. Non Manual Worker; } \\
\text { e. Personal Service Worker; f. Manual Worker; g. Own Account; } \\
\text { f. Farmer; h. Armed Force. }\end{array}$ \\
\hline Income & Continuous & Annual personal income that individuals declare deflated by the price index \\
\hline
\end{tabular}

Source: Bristish Household Panel Survey, Sample period 1991- 2005 
Table 2. Summary Statistics

\begin{tabular}{|c|c|c|c|c|c|}
\hline Variable & Obs & Mean & Std. Dev. & Min & $\operatorname{Max}$ \\
\hline Strict Frustrated Achievers & 71,228 & 0.2002 & 0.4002 & 0 & 1 \\
\hline Life Satisfaction & 71,228 & 5.229 & 1.2880 & 1 & 7 \\
\hline Dummy Age (0-24 yrs) & 71,228 & 0.1186 & 0.3233 & 0 & 1 \\
\hline Dummy Age (25-34 yrs) & 71,228 & 0.1567 & 0.3645 & 0 & 1 \\
\hline Dummy Age (35-44 yrs) & 71,228 & 0.1849 & 0.3882 & 0 & 1 \\
\hline Dummy Age (45-54 yrs) & 71,228 & 0.1535 & 0.3604 & 0 & 1 \\
\hline Dummy Age (55-64 yrs) & 71,228 & 0.1283 & 0.3345 & 0 & 1 \\
\hline Dummy Age (65-111 yrs) & 71,228 & 0.1909 & 0.3930 & 0 & 1 \\
\hline Male & 71,228 & 0.4528 & 0.4977 & 0 & 1 \\
\hline White & 71,228 & 0.3023 & 0.4684 & 0 & 1 \\
\hline England & 71,228 & 0.6307 & 0.4826 & 0 & 1 \\
\hline Wales & 71,228 & 0.1302 & 0.3366 & 0 & 1 \\
\hline Scotland & 71,228 & 0.1519 & 0.3590 & 0 & 1 \\
\hline Northern Ireland & 71,228 & 0.0872 & 0.2818 & 0 & 1 \\
\hline Religious & 71,228 & 0.6135 & 0.4869 & 0 & 1 \\
\hline Children in house & 71,228 & 0.5384 & 0.9450 & 0 & 9 \\
\hline Married & 71,228 & 0.5590 & 0.4965 & 0 & 1 \\
\hline Separated & 71,228 & 0.0202 & 0.1407 & 0 & 1 \\
\hline Divorced & 71,228 & 0.0836 & 0.2769 & 0 & 1 \\
\hline Widowed & 71,228 & 0.0778 & 0.2679 & 0 & 1 \\
\hline Never Married & 71,228 & 0.2592 & 0.4318 & 0 & 1 \\
\hline Higher Education & 71,228 & 0.3790 & 0.4851 & 0 & 1 \\
\hline Employers & 71,228 & 0.0192 & 0.1374 & 0 & 1 \\
\hline Managers & 71,228 & 0.1317 & 0.3382 & 0 & 1 \\
\hline Professional & 71,228 & 0.0435 & 0.2041 & 0 & 1 \\
\hline Non Manual Worker & 71,228 & 0.3679 & 0.4822 & 0 & 1 \\
\hline Personal Service Worker & 71,228 & 0.0729 & 0.2599 & 0 & 1 \\
\hline Manual Worker & 71,228 & 0.2982 & 0.4575 & 0 & 1 \\
\hline Own Account & 71,228 & 0.0488 & 0.2155 & 0 & 1 \\
\hline Farmer & 71,228 & 0.0139 & 0.1173 & 0 & 1 \\
\hline Armed Force & 71,228 & 0.0014 & 0.0370 & 0 & 1 \\
\hline Real Personal Income & 71,228 & 12764.5 & 14315.5 & 0 & $1,151,797$ \\
\hline Relative Income & 71,228 & 1.162397 & 1.240438 & 0 & 144.2319 \\
\hline Job Relative Income & 71,228 & 1.1588 & 1.14988 & 0 & 185.8416 \\
\hline
\end{tabular}


Table 3. Transition matrix for the (1-7) life satisfaction variable*

\begin{tabular}{|c|c|c|c|c|c|c|c|c|c|}
\hline $\begin{array}{c}\text { Life Satisfaction } \\
\text { Levels }\end{array}$ & 1 & 2 & 3 & 4 & 5 & 6 & 7 & & Total \\
\hline \multirow[t]{2}{*}{1} & 31.08 & 12.67 & 15.71 & 15.19 & 11.2 & 6.94 & 7.2 & & 100 \\
\hline & & & & & & & & N. of obs. & 1,152 \\
\hline \multirow[t]{2}{*}{2} & 9.63 & 19.02 & 25.21 & 20.57 & 14.33 & 8.26 & 2.97 & & 100 \\
\hline & & & & & & & & N. of obs. & 1,682 \\
\hline \multirow[t]{2}{*}{3} & 3.46 & 9.66 & 24.74 & 30.24 & 20.52 & 8.5 & 2.89 & & 100 \\
\hline & & & & & & & & N. of obs. & 4,567 \\
\hline \multirow[t]{2}{*}{4} & 1.9 & 3.57 & 12.02 & 32.53 & 33.07 & 13.1 & 3.8 & & 100 \\
\hline & & & & & & & & N. of obs. & 10,728 \\
\hline \multirow[t]{2}{*}{5} & 0.46 & 1.19 & 4.84 & 16.09 & 45.26 & 27.52 & 4.64 & & 100 \\
\hline & & & & & & & & N. of obs. & 22,776 \\
\hline \multirow[t]{2}{*}{6} & 0.29 & 0.52 & 1.67 & 6.18 & 26.45 & 53.4 & 11.48 & & 100 \\
\hline & & & & & & & & N. of obs. & 26,315 \\
\hline \multirow[t]{2}{*}{7} & 0.76 & 0.5 & 1.47 & 3.82 & 10 & 29.01 & 54.45 & & 100 \\
\hline & & & & & & & & N. of obs. & 12,284 \\
\hline \multirow[t]{2}{*}{ Total } & 1.46 & 2.21 & 5.97 & 14.03 & 29.37 & 32.57 & 14.39 & & 100 \\
\hline & & & & & & & & N. of obs. & 79,504 \\
\hline
\end{tabular}

* Current status in row, following year status in column. 
Table 4. Taxonomy and relative weight of the more relevant subgroups based on yearly changes in real household income and life satisfaction (LS)

\begin{tabular}{llll}
\hline & Positive Change in LS & Stationary LS & Negative Change LS \\
Positive Change in Income & Satisfied Achievers & Indifferent achievers & Frustrated achievers \\
Stationary Income & $(16.4$ percent $)$ & $(29.76$ percent $)$ & $(17.5$ percent $)$ \\
Negative Change in Income & Satisfied losers & Indifferent losers & Frustrated losers \\
& $(9.2$ percent $)$ & $(16$ percent $)$ & $(10.7$ percent $)$ \\
\hline \hline
\end{tabular}

Table 5. Locations and Probabilities for Different Numbers of Integration Points (Groups)

\begin{tabular}{lrcccccc}
\hline & & 1 & 2 & 3 & 4 & 5 & Log Likelihood \\
\hline Model with 2 groups & Locations & -3.4 & 0.059 & & & & -125992.19 \\
& Probabilities & 0.02 & 0.98 & & & & \\
Model with 3 groups & Locations & -3.74 & -3.741 & -0.029 & & & -125684.69 \\
& Probabilities & 0.01 & 0.026 & 0.957 & & & \\
Model with 4 groups & Locations & -0.001 & 3.39 & -7.02 & -1.81 & & -125597.68 \\
& Probabilities & 0.94 & 0.026 & 0.006 & 0.024 & & \\
Model with 5 groups & Locations & 2.34 & -1.84 & -7.05 & 8.75 & -0.0339 & -125507.72 \\
& Probabilities & 0.032 & 0.024 & 0.006 & 0.931 & 0.931 & \\
& & & & & & & \\
\hline \hline
\end{tabular}

Table 6. Income-Happiness: Fixed Effect and Mixture Model

\begin{tabular}{|c|c|c|c|c|}
\hline \multicolumn{5}{|c|}{ Dep. Variable: One Year Change in Life Satisfaction } \\
\hline & Mixture Model & $t$-stat & Fixed Effects & $t$-stat \\
\hline Intercept & -0.041 & -9.72 & -0.04 & -8.72 \\
\hline \multirow[t]{2}{*}{ Log Household Income $t-1$} & 0.0033 & 0.46 & 0.0339 & 3.96 \\
\hline & Location & Probability & $F-$ test & 15.71 \\
\hline Group 1 & 0.059 & 0.98 & & \\
\hline Group 2 & -3.4 & 0.02 & & \\
\hline \multicolumn{5}{|c|}{$\begin{array}{l}\text { Table Legend: Results from the mixture approach are provided in the first column and compared } \\
\text { with a fixed effect benchmark in the second column. In the second part of the first column } \\
\text { two clusters are identified. The coefficient of the income effect for each of the two clusters is given } \\
\text { from the cluster specific coefficient plus the average coefficient. } \\
F \text { - test on the joint hypothesis that the coefficients on the locations are zero }\end{array}$} \\
\hline
\end{tabular}


Table 7. Summary Statistics and Confidence Interval for the 1st and the 2nd group

\begin{tabular}{|c|c|c|c|c|}
\hline & \multicolumn{2}{|c|}{ Easterlin-Types } & \multicolumn{2}{|c|}{ Frustrated Achievers } \\
\hline Variable & Mean & {$[95 \%$ Conf.Interval $]$} & Mean & [95\% Conf.Interval] \\
\hline Life Satisfaction & $4.17^{*}$ & 3.9234 .424 & $5.22 *$ & 5.2115 .237 \\
\hline Dummy Age (0-24 yrs) & $.066^{*}$ & 3.9234 .424 & $.121^{*}$ & .1183 .1248 \\
\hline Dummy Age (25-34 yrs) & 0.111 & .0733 .1488 & 0.155 & .1520 .1593 \\
\hline Dummy Age (35-44 yrs) & 0.207 & .1587 .2560 & 0.186 & .1826 .1905 \\
\hline Dummy Age (45-54 yrs) & 0.013 & .0957 .1783 & 0.154 & .1506 .1579 \\
\hline Dummy Age (55-64 yrs) & 0.155 & .1120 .1990 & 0.125 & .1226 .1293 \\
\hline Male & $.300^{*}$ & .2449 .3550 & $.457^{*}$ & .1226 .1293 \\
\hline White & 0.144 & .1022 .1866 & 0.18 & .4523 .4624 \\
\hline England & 0.542 & .4828 .6026 & 0.627 & .1764 .1841 \\
\hline Wales & 0.163 & . 2080 & 0.13 & .1266 .1334 \\
\hline Scotland & $.252^{*}$ & .2005 .3050 & $.152 *$ & .1493 .1566 \\
\hline Religious & 0.655 & .5985 .7125 & 0.627 & .6130 .6228 \\
\hline Children in house & $.796^{*}$ & 6539.9386 & $.526^{*}$ & .5171 .5359 \\
\hline Married & 0.533 & .4734 .5932 & 0.558 & .5537 .5637 \\
\hline Separated & 0.022 & .0045 .0399 & 0.02 & .0192.0220 \\
\hline Divorced & $.177^{*}$ & .1318 .2236 & $.084^{*}$ & .0817 .0873 \\
\hline Widowed & 0.114 & .0765 .1530 & 0.075 & .0729.0782 \\
\hline Higher Education & $.203^{*}$ & .1553 .2520 & $.371^{*}$ & .3665 .3763 \\
\hline Employers & 0.027 & .1553 .2520 & 0.018 & .0174 .0202 \\
\hline Managers & 0.054 & .02675 .0830 & 0.129 & .1262 .1332 \\
\hline Professional & 0.003 & -.0038 .0116 & 44 & 0421.0463 \\
\hline Non Manual Worker & 0.231 & .1792 .2834 & 365 & .3606 .3705 \\
\hline Personal Service Worker & 0.227 & .1756 .2792 & 70 & .0680 .0733 \\
\hline Manual Worker & 352 & .2938 .4119 & 301 & .2971 .3066 \\
\hline Own Account & 85 & .0516 .1186 & 51 & .0494 .0539 \\
\hline Farmer & 11 & -.0015 .0250 & 13 & 0120.0143 \\
\hline Log Real Personal Income & $8.64^{*}$ & 8.5448 .748 & $9.05^{*}$ & 9.0459 .068 \\
\hline Log Relative Income & $-0.376^{*}$ & -0.7523 & $-0.142^{*}$ & -0.2842 \\
\hline Log Job Relative Income & $-0.281^{*}$ & -0.5638 & $-0.124^{*}$ & -0.249 \\
\hline
\end{tabular}

* cluster means are significantly different at 5 percent.

Log Relative Income: log of the "people-like-me" relative income

(peer groups based on interacting gender, education, location and age cohorts).

Log Job Relative Income: log of the "peer-effect" relative income

(peer groups based on gender, age cohorts and working environment).

DLog Relative Income: first difference log of "people-like-me" relative income variable.

DLog Job Relative Income: first difference log of "peer-effect" relative income variable. 
Table 8. Pooled Logit Estimates

\begin{tabular}{|c|c|c|c|}
\hline \multicolumn{4}{|c|}{ (Dependent Variable: Affiliation to the Cluster of FA) } \\
\hline Variable & Model I & Model II & Model III \\
\hline Age $0-24$ & $\begin{array}{c}-0.625^{*} \\
(0.36)\end{array}$ & $\begin{array}{l}-0.833^{* *} \\
(0.39)\end{array}$ & $\begin{array}{l}-0.837^{* *} \\
(0.39)\end{array}$ \\
\hline Age 25-34 & $\begin{array}{l}-0.438^{*} \\
(0.26)\end{array}$ & $\begin{array}{l}-0.519^{* *} \\
(0.26)\end{array}$ & $\begin{array}{l}-0.517^{* *} \\
(0.26)\end{array}$ \\
\hline Age $35-44$ & $\begin{array}{l}-0.353 \\
(0.22)\end{array}$ & $\begin{array}{l}-0.434^{*} \\
(0.22)\end{array}$ & $\begin{array}{l}-0.428^{*} \\
(0.22)\end{array}$ \\
\hline Age $45-54$ & $\begin{array}{l}-0.174 \\
(0.21)\end{array}$ & $\begin{array}{l}-0.460^{* *} \\
(0.23)\end{array}$ & $\begin{array}{l}-0.445^{*} \\
(0.23)\end{array}$ \\
\hline Age 55-64 & $\begin{array}{l}0.143 \\
(0.20)\end{array}$ & $\begin{array}{l}0.139 \\
(0.20)\end{array}$ & $\begin{array}{l}0.145 \\
(0.20)\end{array}$ \\
\hline Male & $\begin{array}{l}-0.566^{* * *} \\
(0.15)\end{array}$ & $\begin{array}{l}-0.517^{* * *} \\
(0.16)\end{array}$ & $\begin{array}{l}-0.513^{* * *} \\
(0.16)\end{array}$ \\
\hline White & $\begin{array}{l}-0.404^{* *} \\
(0.20)\end{array}$ & $\begin{array}{l}-0.393^{*} \\
(0.20)\end{array}$ & $\begin{array}{l}-0.390^{*} \\
(0.20)\end{array}$ \\
\hline England & $\begin{array}{l}0.599 * \\
(0.34)\end{array}$ & $\begin{array}{l}0.503 \\
(0.34)\end{array}$ & $\begin{array}{l}0.472 \\
(0.34)\end{array}$ \\
\hline Wales & $\begin{array}{l}0.827^{* *} \\
(0.36)\end{array}$ & $\begin{array}{l}0.805^{* *} \\
(0.37)\end{array}$ & $\begin{array}{l}0.783^{* *} \\
(0.37)\end{array}$ \\
\hline Scotland & $\begin{array}{l}1.346^{* * *} \\
(0.35)\end{array}$ & $\begin{array}{l}1.266^{* * *} \\
(0.35)\end{array}$ & $\begin{array}{l}1.251^{\text {*** }} \\
(0.35)\end{array}$ \\
\hline Religious & $\begin{array}{l}0.0173 \\
(0.14)\end{array}$ & $\begin{array}{l}-0.0448 \\
(0.14)\end{array}$ & $\begin{array}{l}-0.0440 \\
(0.14)\end{array}$ \\
\hline Children in house & $\begin{array}{l}0.311^{* * *} \\
(0.071)\end{array}$ & $\begin{array}{l}0.332^{* * *} \\
(0.072)\end{array}$ & $\begin{array}{l}0.334^{* * *} \\
(0.072)\end{array}$ \\
\hline Married & $\begin{array}{l}0.107 \\
(0.24)\end{array}$ & $\begin{array}{l}0.0160 \\
(0.24)\end{array}$ & $\begin{array}{l}0.0241 \\
(0.24)\end{array}$ \\
\hline Separated & $\begin{array}{l}-0.420 \\
(0.55)\end{array}$ & $\begin{array}{l}-0.364 \\
(0.55)\end{array}$ & $\begin{array}{l}-0.366 \\
(0.55)\end{array}$ \\
\hline Divorced & $\begin{array}{l}0.788^{* * *} \\
(0.26)\end{array}$ & $\begin{array}{l}0.827^{* * *} \\
(0.27)\end{array}$ & $\begin{array}{l}0.828^{* * *} \\
(0.27)\end{array}$ \\
\hline Widowed & $\begin{array}{l}0.222 \\
(0.30)\end{array}$ & $\begin{array}{l}0.273 \\
(0.31)\end{array}$ & $\begin{array}{l}0.262 \\
(0.31)\end{array}$ \\
\hline
\end{tabular}


Table 8. Continue Pooled Logit Estimates

\begin{tabular}{|c|c|c|c|}
\hline Variable & Model I & Model II & Model III \\
\hline HigherEducation & $\begin{array}{l}-0.557^{* * *} \\
(0.16)\end{array}$ & $\begin{array}{l}-0.601^{* * *} \\
(0.17)\end{array}$ & $\begin{array}{l}-0.533^{* * *} \\
(0.16)\end{array}$ \\
\hline Employers & $\begin{array}{l}0.415 \\
(0.70)\end{array}$ & $\begin{array}{l}0.432 \\
(0.70)\end{array}$ & $\begin{array}{l}0.381 \\
(0.70)\end{array}$ \\
\hline Managers & $\begin{array}{l}-0.623 \\
(0.64)\end{array}$ & $\begin{array}{l}-0.477 \\
(0.65)\end{array}$ & $\begin{array}{l}-0.611 \\
(0.64)\end{array}$ \\
\hline Professional & $\begin{array}{l}-1.892 \\
(1.16)\end{array}$ & $\begin{array}{l}-1.745 \\
(1.16)\end{array}$ & $\begin{array}{l}-1.889 \\
(1.16)\end{array}$ \\
\hline Non Manual Worker & $\begin{array}{l}-0.506 \\
(0.60)\end{array}$ & $\begin{array}{l}-0.444 \\
(0.60)\end{array}$ & $\begin{array}{c}-0.504 \\
(0.60)\end{array}$ \\
\hline Personal Service Worker & $\begin{array}{l}0.940 \\
(0.60)\end{array}$ & $\begin{array}{l}0.993^{*} \\
(0.60)\end{array}$ & $\begin{array}{l}0.985 \\
(0.60)\end{array}$ \\
\hline Manual Worker & $\begin{array}{l}0.0545 \\
(0.59)\end{array}$ & $\begin{array}{l}0.0867 \\
(0.59)\end{array}$ & $\begin{array}{l}0.0770 \\
(0.59)\end{array}$ \\
\hline OwnAccount & $\begin{array}{l}0.462 \\
(0.62)\end{array}$ & $\begin{array}{l}0.142 \\
(0.63)\end{array}$ & $\begin{array}{l}0.138 \\
(0.63)\end{array}$ \\
\hline Log Real Household Income & $\begin{array}{l}-0.216^{* * *} \\
(0.065)\end{array}$ & $\begin{array}{l}-0.164^{* *} \\
(0.076)\end{array}$ & $\begin{array}{l}-0.170^{* *} \\
(0.076)\end{array}$ \\
\hline Log Relative Real Personal Income & & $\begin{array}{l}-0.183^{* * *} \\
(0.071)\end{array}$ & \\
\hline DLog Relative Real Personal Income & & $\begin{array}{l}0.0983 \\
(0.073)\end{array}$ & \\
\hline Log Relative Job Income & & & $\begin{array}{l}-0.158^{* *} \\
(0.073)\end{array}$ \\
\hline DLog Relative Job Income & & & $\begin{array}{l}0.0614 \\
(0.076)\end{array}$ \\
\hline Constant & $\begin{array}{l}-3.826^{* * *} \\
(0.84)\end{array}$ & $\begin{array}{l}-4.106^{* * *} \\
(0.89)\end{array}$ & $\begin{array}{l}-4.014^{* * *} \\
(0.89)\end{array}$ \\
\hline Observations & 35979 & 34900 & 34900 \\
\hline
\end{tabular}

Standard errors in parentheses

*** $\mathrm{p}<0.01, * * \mathrm{p}<0.05, * \mathrm{p}<0.1$ 
Table 9. Random Effect Logit Estimates

(Dependent Variable: Affiliation to the Cluster of FA)

\begin{tabular}{|c|c|c|c|}
\hline Variable & Model I & Model II & Model III \\
\hline \multirow[t]{2}{*}{ Age $0-24$} & -0.268 & -0.524 & -0.535 \\
\hline & $(-0.6)$ & $(-1.08)$ & $(-1.1)$ \\
\hline \multirow[t]{2}{*}{ Age 25-34 } & -0.274 & -0.313 & -0.317 \\
\hline & $(-0.79)$ & $(-0.9)$ & $(-0.91)$ \\
\hline \multirow[t]{2}{*}{ Age $35-44$} & -0.274 & -0.426 & -0.427 \\
\hline & $(-1.13)$ & $(-1.38)$ & $(-1.38)$ \\
\hline \multirow[t]{2}{*}{ Age $45-54$} & -0.102 & -0.308 & -0.3 \\
\hline & $(-0.35)$ & $(-1.01)$ & $(-0.98)$ \\
\hline \multirow[t]{2}{*}{ Age 55-64 } & 0.099 & 0.092 & 0.097 \\
\hline & $(-0.35)$ & $(-0.33)$ & $(-0.35)$ \\
\hline \multirow[t]{2}{*}{ Male } & -0.343 & -0.339 & -0.338 \\
\hline & $(-1.59)$ & $(-1.52)$ & $(-1.52)$ \\
\hline \multirow{2}{*}{ White } & -0.305 & -0.253 & -0.254 \\
\hline & $(-1.14)$ & $(-0.94)$ & $(-0.94)$ \\
\hline \multirow[t]{2}{*}{ England } & 0.081 & -0.002 & -0.044 \\
\hline & $(-0.2)$ & $(-0.01)$ & $(-0.11)$ \\
\hline \multirow[t]{2}{*}{ Wales } & 0.754 & 0.745 & 0.711 \\
\hline & $(-1.7)$ & $(-1.67)$ & $(-1.59)$ \\
\hline \multirow[t]{2}{*}{ Scotland } & 1.12 & 1.061 & 1.035 \\
\hline & $(2.64)^{* *}$ & $(2.49)^{* *}$ & $(2.42)^{* *}$ \\
\hline \multirow[t]{2}{*}{ Religious } & 0.009 & -0.05 & -0.048 \\
\hline & $(-0.05)$ & $(-0.24)$ & $(-0.23)$ \\
\hline \multirow[t]{2}{*}{ Children in house } & 0.291 & 0.304 & 0.306 \\
\hline & $(2.83)^{* *}$ & $(2.9)^{* *}$ & $(2.93)^{* *}$ \\
\hline \multirow[t]{2}{*}{ Married } & 0.1 & 0.05 & 0.052 \\
\hline & $(-0.31)$ & $(-0.16)$ & $(-0.16)$ \\
\hline \multirow[t]{2}{*}{ Separated } & -0.275 & -0.218 & -0.214 \\
\hline & $(-0.4)$ & $(-0.31)$ & $(-0.31)$ \\
\hline \multirow[t]{2}{*}{ Divorced } & 0.68 & 0.745 & 0.745 \\
\hline & $(-1.78)$ & $(-1.93)$ & $(-1.93)$ \\
\hline \multirow[t]{2}{*}{ Widowed } & 0.601 & 0.695 & 0.687 \\
\hline & $(-1.47)$ & $(-1.67)$ & $(-1.65)$ \\
\hline
\end{tabular}


Table 9. Cont. Random Effect Logit Estimates

\begin{tabular}{|c|c|c|c|}
\hline \multicolumn{4}{|c|}{ (Dependent Variable: Affiliation to the Cluster of FA) } \\
\hline Variable & Model I & Model II & \\
\hline \multirow[t]{2}{*}{ Higher Education } & -0.505 & -0.612 & -0.531 \\
\hline & $(-2.21)^{*}$ & $(-2.57)^{* *}$ & $(-2.24)^{*}$ \\
\hline \multirow[t]{2}{*}{ Employers } & 0.374 & 0.386 & 0.318 \\
\hline & $(-0.42)$ & $(-0.42)$ & $(-0.35)$ \\
\hline \multirow[t]{2}{*}{ Managers } & -0.832 & -0.674 & -0.834 \\
\hline & $(-1.02)$ & $(-0.82)$ & $(-1.01)$ \\
\hline \multirow[t]{2}{*}{ Professional } & -1.511 & -1.333 & -1.505 \\
\hline & $(-1.2)$ & $(-1.06)$ & $(-1.2)$ \\
\hline \multirow[t]{2}{*}{ NonManualWorker } & -0.546 & -0.484 & -0.555 \\
\hline & $(-0.72)$ & $(-0.63)$ & $(-0.73)$ \\
\hline \multirow[t]{2}{*}{ PersonalServiceWorker } & $(0.78)$ & $(0.817)$ & $(0.811)$ \\
\hline & -1 & -1.04 & -1.03 \\
\hline \multirow[t]{2}{*}{ ManualWorker } & -0.116 & -0.075 & -0.082 \\
\hline & $(-0.16)$ & $(-0.1)$ & $(-0.11)$ \\
\hline \multirow[t]{2}{*}{ OwnAccount } & 0.118 & -0.102 & -0.103 \\
\hline & $(-0.15)$ & $(-0.12)$ & $(-0.13)$ \\
\hline \multirow[t]{2}{*}{ Log Real Personal Income } & -0.196 & -0.12 & -0.121 \\
\hline & $(-1.99)^{*}$ & $(-1.05)$ & $(-1.06)$ \\
\hline \multirow[t]{2}{*}{ Log Relative Real Personal Income } & & -0.23 & \\
\hline & & $(-2.27)^{*}$ & \\
\hline \multirow[t]{2}{*}{ DLog Relative Real Personal Income } & & 0.117 & \\
\hline & & $(-1.19)$ & \\
\hline \multirow[t]{2}{*}{ Log Relative Job Income } & & & -0.219 \\
\hline & & & $(-2.13)$ \\
\hline \multirow[t]{2}{*}{ DLog Job Relative Income } & & & 0.092 \\
\hline & & & $(-0.91)$ \\
\hline \multirow[t]{2}{*}{ Constant } & -5.61 & -6.10 & -6.03 \\
\hline & $(-4.93)^{* * *}$ & $(-4.99)^{* * *}$ & $(-4.97)^{* * *}$ \\
\hline \multirow[t]{2}{*}{$\sigma_{e}$} & 1.16 & 1.15 & 1.15 \\
\hline & $(33.47)^{* * *}$ & $(32.59)^{* * *}$ & $(32.62)^{* * *}$ \\
\hline $\mathrm{N}$ & 35,979 & 34,900 & 34,900 \\
\hline
\end{tabular}

Standard errors in parentheses

*** $\mathrm{p}<0.01,{ }^{* *} \mathrm{p}<0.05,{ }^{*} \mathrm{p}<0.1$ 